\title{
Dielectrics of lead zirconate bonded with barium borate glass
}

\author{
K SINGH and ARUNA INDURKAR \\ Department of Physics, Nagpur University, Nagpur 440 010, India \\ MS received 25 May 1987; revised 11 July 1988
}

\begin{abstract}
Dielectric constant variation with temperature and frequency is reported for barium-borate glass-bonded lead zirconate. Lowering of the relative permittivity of the ceramic is attributed to the presence of the glass.
\end{abstract}

Keywords. Liquid phase sintering; dielectric constant; ceramics; lead zirconate; barium borate glass.

\section{Introduction}

Liquid phase sintering (LPS) technique plays a predominant role in the current technology of metallurgy and ceramics because it reduces the sintering temperature, modifies the properties of the material under preparation and provides better mechanical strength and higher reproducibility (Fukami 1974). Following LPS, lead zirconate was bonded with glass consisting mainly of oxides of heavy metals such as $\mathrm{PbO}$ and $\mathrm{Bi}_{2} \mathrm{O}_{3}$ with about $10 \%$ of glass formers $\left(\mathrm{SiO}_{2}, \mathrm{~B}_{2} \mathrm{O}_{3}\right)$. Lead zirconate bonded with this glass was found to be suitable for energy storage with energy density as $2 \mathrm{~J} / \mathrm{cm}^{3}$ (Burn 1971). It was reported that the energy density value of borosilicate with $\mathrm{PbO}, \mathrm{Bi}_{2} \mathrm{O}_{3}$ glass-bonded barium titanate to be the same and $30 \%$ lower in the case of $4 \mathrm{BaO} \cdot \mathrm{Al}_{2} \mathrm{O}_{3} \cdot 2 \mathrm{~B}_{2} \mathrm{O}_{3}$ glass bonded $\mathrm{SrTiO}_{3}$ (Burn and Smyth 1972). The glass used earlier was a multicomponent system and it was further reported that barium from the glass reacts with lead zirconate and forms lead-barium zirconate. In order to explore this possibility, a two-component $\mathrm{BaO}$ $\mathrm{B}_{2} \mathrm{O}_{3}$ glass system was prepared. The glass was added in the ratio of 0.5 and $10 \mathrm{wt} \%$. The dielectric constant was studied as a function of temperature and frequency.

\section{Experimental details}

Lead zirconate ceramic was prepared using the technique described earlier (Singh et al 1982). For bonding, the glass system chosen was $\mathrm{BaO} \cdot \mathrm{B}_{2} \mathrm{O}_{3}(10: 90,20: 80$ and $30: 70 \mathrm{~mol} \%$ respectively). The ingredients were ground thoroughly under acetone, dried and heated moderately in a controlled and thermally sensored electric furnace. The melting point ranged between 800 and $900^{\circ} \mathrm{C}$. The melt was soaked at that temperature for $1 \mathrm{~h}$ to allow homogenization. Glass was then quenched in an aluminium mould at room temperature. In order to use it as a binder, quenched glass pieces were crushed to fine powder.

Finely crushed powder of lead zirconate and glass were passed through a sieve (450 mesh size) and weighed in the desired ratio and ground well. The process of mixing continued for a longer time to ensure perfect mixing of the ingredients. This 
mixed and powdered mass was pressed isostatically in a steel die and punched at 10 tons $/ \mathrm{cm}^{2}$ resulting in pellets of $13 \mathrm{~mm}$ dia and 0.5 to $1 \mathrm{~mm}$ in thickness. These pellets were subjected to different heat treatments for a fixed duration of $1 \mathrm{~h}$. The sintering temperatures mainly depended on the glass content and the melting point of the glass. Generally it was observed that as the glass content was increased the sintering temperature decreased. The optimized sintering temperature is given in table 1. The sintered pellets were silver-coated and baked at $150^{\circ} \mathrm{C}$ for $2 \mathrm{~h}$ to achieve perfect ohmic contact. Dielectric constant measurements are reported as a function of temperature and frequency with a input voltage of 1 volt by means of Hewlett-Packard multi-frequency inductance-capacitance resistance (LCR) meter 4261A and Hewlett-Packard impedence analyser 4192A with input voltage of $500 \mathrm{mV}$ respectively. The measuring temperature and frequency ranged from room temperature to $300^{\circ} \mathrm{C}$ and $100 \mathrm{~Hz}$ to $100 \mathrm{kHz}$.

\section{Results and discussion}

The functional dependence of dielectric constant on temperature and frequency was studied experimentally for pure and glass-bonded lead zirconate at a fixed frequency of $1 \mathrm{kHz}$ from room temperature to $300^{\circ} \mathrm{C}$ and at room temperature from $100 \mathrm{~Hz}$ to $100 \mathrm{kHz}$ respectively.

Figure 1 depicts the dependence of dielectric constant for pure lead zirconate in the temperature range from room temperature to $300^{\circ} \mathrm{C}$ at $1 \mathrm{kHz}$. It is seen that for pure $\mathrm{PbZrO}_{3}$ beyond $200^{\circ} \mathrm{C}$, the increase in $\varepsilon$ is very rapid till $230^{\circ} \mathrm{C}$ at which it reaches a maximum value of 3200 and then decreases. The value of Curie constant was found to be $6 \times 10^{4} \mathrm{C}$ and the Curie-Weiss temperature $T_{0}$ was $207^{\circ} \mathrm{C}$.

Figures 2-4 illustrate the relative permittivity variation vs temperature of 0.5 and $10 \mathrm{wt} \%$ of $\mathrm{PbZrO}_{3}$ bonded with glasses I-III. Table 2 gives the data regarding the peak value of the dielectric constant $\varepsilon_{\text {peak }}, T_{c}, T_{0}$ and $C$ for all the samples.

Figure 5 depicts the frequency variation of the dielectric constant for pure and glass-bonded samples. In the frequency range studied, the dielectric constant is independent of frequency and hence did not merit further attention. For $0.5 \mathrm{wt} \%$ glass addition the value of $\varepsilon_{\text {peak }}$ for $\mathrm{PbZrO}_{3}$ bonded with glass systems I, II and III are found to be 670,3238 and 703 respectively and that for $10 \mathrm{wt} \%$ glass addition it is 150,2992 and 669 respectively.

In the present case, the peak value of the dielectric constant is understandably lower than that for high purity material (Roberts 1950; Shirane et al 1951;

Table 1. Optimized sintering temperatures.

\begin{tabular}{lccc}
\hline $\begin{array}{l}\text { Glass } \\
\text { No. }\end{array}$ & $\begin{array}{c}\text { Glass } \\
\text { composition } \\
\text { BaO- } \mathrm{B}_{2} \mathrm{O}_{3}\end{array}$ & $\begin{array}{c}\text { Weight } \% \text { of } \\
\text { added glass }\end{array}$ & $\begin{array}{c}\text { Optimized } \\
\text { sintering } \\
\text { temperature }\left({ }^{\circ} \mathrm{C}\right)\end{array}$ \\
\hline I & $10: 90$ & 0.5 & 950 \\
II & $20: 80$ & 10 & 875 \\
& & 0.5 & 900 \\
III & $30: 70$ & 10 & 800 \\
& & 0.5 & 800 \\
& & 10 & 725 \\
\hline
\end{tabular}




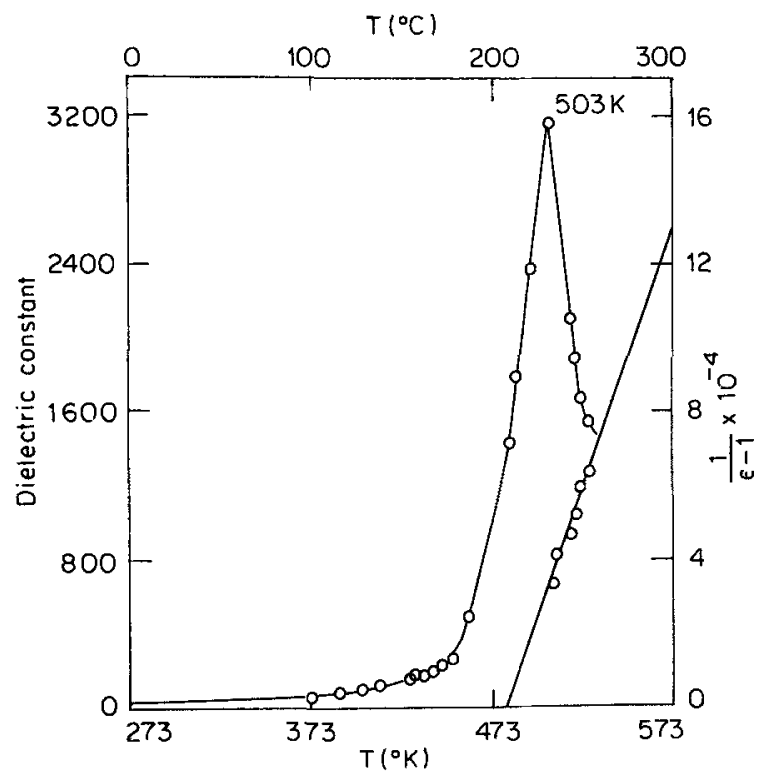

Figure 1. Dielectric constant variation with temperature for pure lead zirconate.

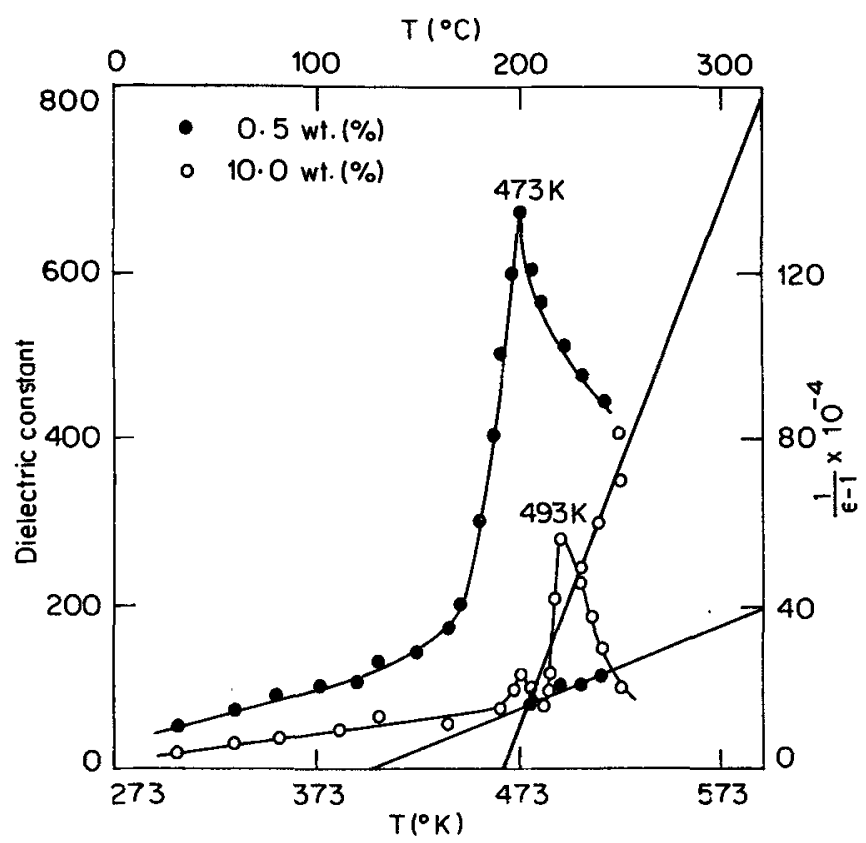

Figure 2. Dielectric constant variation with temperature for lead zirconate bonded with glass 1 .

Weirauch and Tennery 1970). Burn (1971) reasoned that the permittivity of the ceramic gets diluted by the addition of the glass and an extra peak appears in the $\mathrm{PbZrO}_{3}$ matrix. It has been attributed to the reaction of the glass with ceramic. 


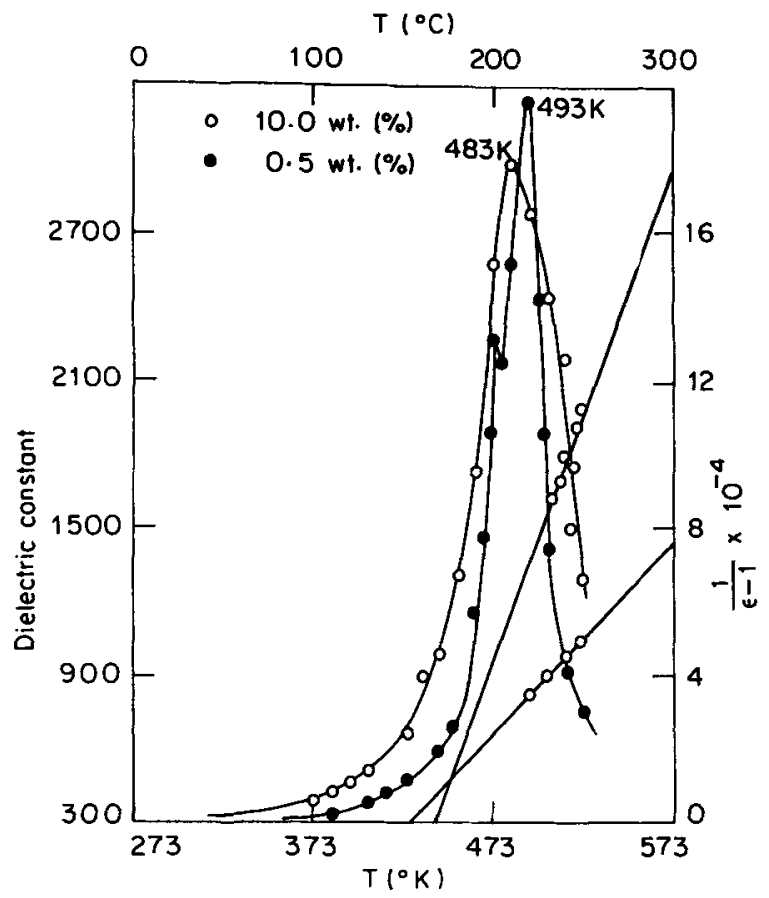

Figure 3. Dielectric constant variation with temperature for lead zirconate bonded with glass II.

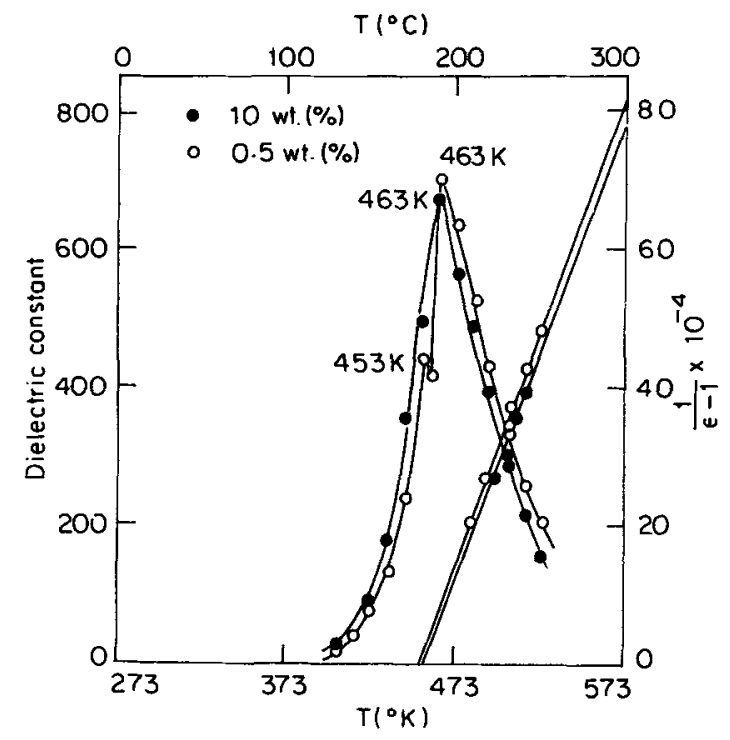

Figure 4. Dielectric constant variation with temperature for lead zirconate bonded with glass III. 
Table 2. Compositional dependence of $\varepsilon_{\text {peak }}, T_{c}, T_{0}, C$.

\begin{tabular}{|c|c|c|c|c|c|c|c|}
\hline \multirow[b]{3}{*}{$\%$ of glass doping } & \multirow{3}{*}{$\begin{array}{c}\begin{array}{c}\text { Pure } \\
\mathrm{PbZrO}_{3}\end{array} \\
-\end{array}$} & \multicolumn{6}{|c|}{ Glasses } \\
\hline & & \multicolumn{2}{|r|}{ I } & \multicolumn{2}{|c|}{ II } & \multicolumn{2}{|c|}{ III } \\
\hline & & 0.5 & 10 & 0.5 & 10 & 0.5 & 10 \\
\hline$\varepsilon_{\text {peak }}$ & 3200 & 670 & 280 & 3238 & 2992 & 703 & 669 \\
\hline $\begin{array}{l}\text { Transition } \\
\text { temperature }\left({ }^{\circ} \mathrm{C}\right)\end{array}$ & 230 & 200 & 220 & 220 & 210 & 190 & 190 \\
\hline$C\left({ }^{\circ} \mathrm{C}\right)$ & $6 \times 10^{4}$ & $5 \times 10^{4}$ & $0.83 \times 10^{4}$ & $1.35 \times 10^{5}$ & $0.5 \times 10^{5}$ & $6.2 \times 10^{5}$ & $6.5 \times 10^{5}$ \\
\hline$T_{0}\left({ }^{\circ} \mathrm{C}\right)$ & 207 & 124 & 190 & 166 & 154 & 178 & 181 \\
\hline $\begin{array}{l}\text { Width of ferroelectric } \\
\text { region }\left({ }^{\circ} \mathrm{C}\right)\end{array}$ & - & - & 20 & 18 & - & 10 & - \\
\hline Density $\mathrm{g} / \mathrm{cm}^{3}$ & 90 & 90 & 80 & 81 & 80 & 76 & 74 \\
\hline
\end{tabular}

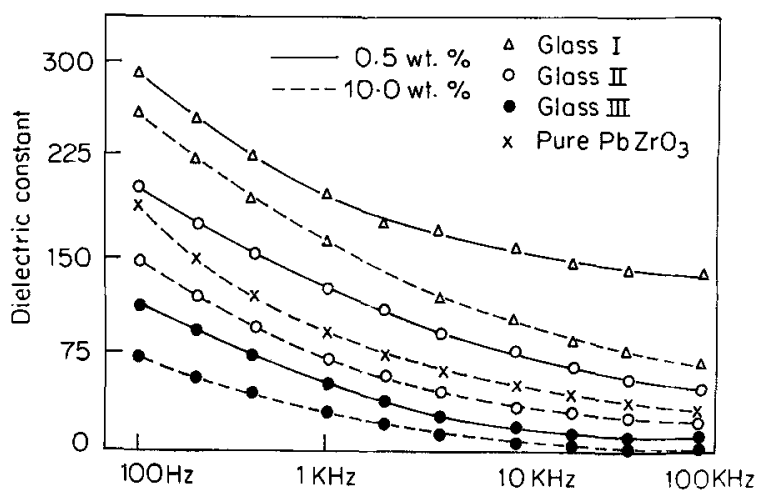

Figure 5. Frequency variation of dielectric constant for unbended and barium borate glass-bonded lead zirconate.

In the present study, the barium-borate glass was found to be a viscous glass. With the increase of $\mathrm{BaO}$ from $10 \mathrm{~mol} \%$ to $30 \mathrm{~mol} \%$, the amount of the viscous flow during sintering increases. According to Subbarao (1979) the liquidous flow should have minimum viscosity at the sintering temperature so that the amount of liquid is kept to a minimum. The barium-borate glass being very viscous, it might not be getting creaped across the grain boundaries of whole of the pellet, since after the sintering the pellet is suddenly quenched to room temperature. Because of the collection of the glassy phase on some parts of the pellet, there might be an overall decrease in the value of $\varepsilon_{r}$.

SEM photographs of pure and glass-bonded lead zirconate (figure 6) indicate that due to the addition of glass there is a change in the packing density of the material and an increase in the grain size. Further work in this direction is in progress.

Table 2 indicates that the density of the lower glass $(0.5 \mathrm{wt} \%)$ added sample is greater than that of the higher glass $(10 \mathrm{wt} \%)$ added sample. Theoretical considerations of the model bearing on the influence of the quantity of liquid on the degree of densification conclude that the density of the samples sintered in the presence of liquid depends on its amount (Kingery 1959). In the case of spinels it has been 

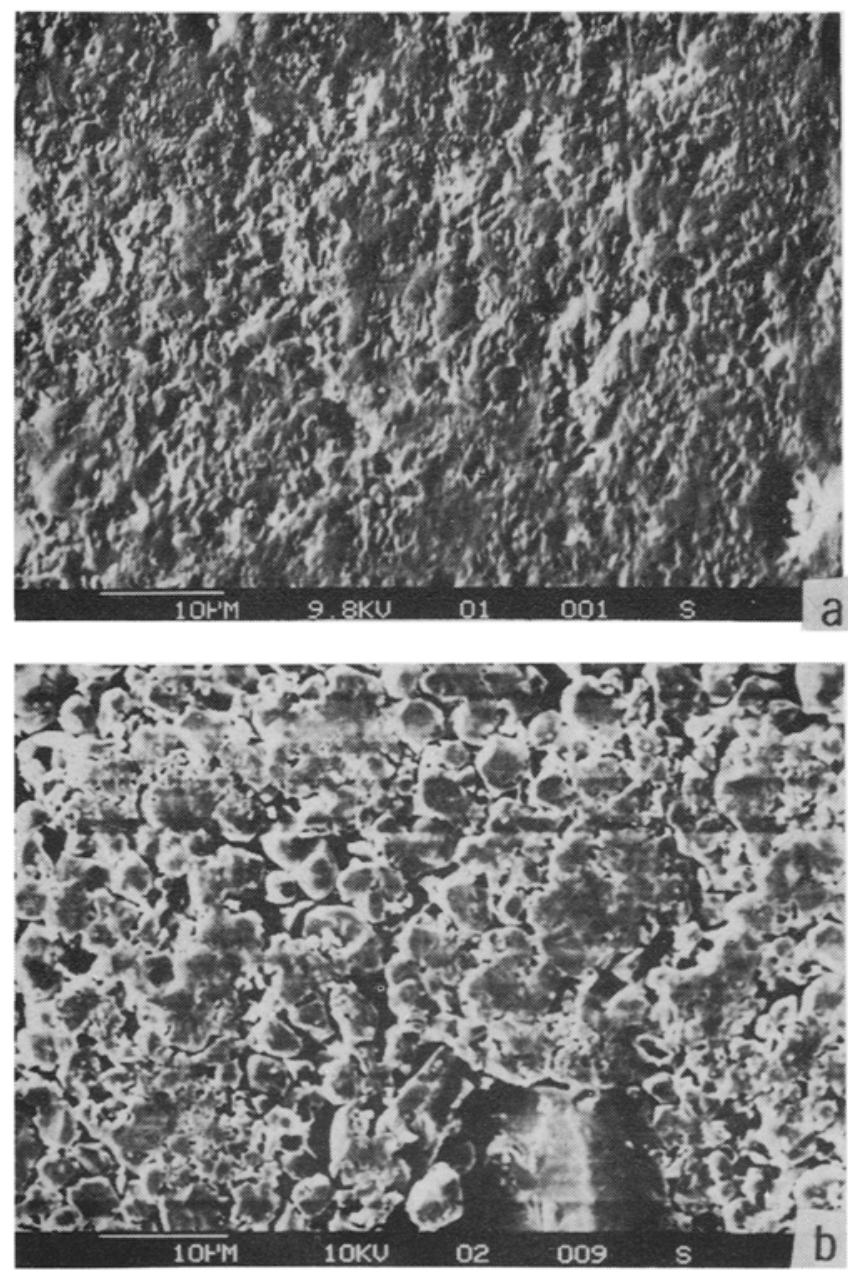

Figure 6. SEM photographs of pure and glass-bonded lead zirconate.

shown that by the presence of greater quantity of additives (i.e. amount of liquid) above the optimal one, a decrease in density is observed. This behaviour was explained by setting up the repulsion forces between particles in samples when the amount of liquid is greater than the optimal quantity for densification (Eremenko et al 1968). It is further reported that the microstructural analysis of the samples sintered in the presence of different quantity of additives showed that the quantity of liquid within the samples affected the grain growth as well as the open porosity. Table 2 illustrates that for lower glass additions, the density and $\varepsilon_{r}$ are higher than that of $10 \mathrm{wt} \%$ glass addition. This factor is reasonable because higher packing density would result in a larger value of $\varepsilon_{r}$.

\section{Conclusion}

The present study shows that there is an overall decrement in the value of dielectric 
constant of lead zirconate after the glass addition. The glass addition needs to be tried over the entire range, i.e. between 0.5 and $10 \mathrm{wt} \%$.

\section{Acknowledgement}

One of the authors (AI) is thankful to CSIR, New Delhi for the award of a fellowship.

\section{References}

Burn I 1971 J. Am. Ceram. Soc. 50501

Burn I and Smyth D 1972 J. Mater. Sci. 7339

Eremenko V, Naidich I and Lavrienko I 1968 "Spekanie V prisustvii zhidkoi metalliches-koi fazi" Izd. Naukova dumka, Kiev

Fukami T 1974 Abstr. Trans. Inst. Electron. Commun. Eng. Jpn. 5731

Kingery W 1959 J. Appl. Phys. 30301

Roberts S $1950 \mathrm{~J}$. Am. Ceram. Soc. 3363

Shirane G 1952 Phys. Rev. 86219

Shirane G, Sawaguchi E and Takagi Y 1951 Phy. Rev. 84476

Singh K, Indurkar A and Deshmukh K G 1982 Ferroelectrics 45219

Subbarao E C 1979 Presented at the Symp. Sintering and Sintered Prod. BARC, Bombay, October 29-31

Weirauch D and Tennery V $1970 \mathrm{~J}$. Am. Ceram. Soc. 53229 